\title{
Plant Growth Regulators Affect Germination and Main Carbon-Nitrogen Metabolites of Potato Tubers
}

\author{
Zhong Lei ${ }^{1}$, Wang Liangjun ${ }^{2}$, Yuan Jichao ${ }^{1}$, Zheng Shunlin ${ }^{1,3,}{ }^{*}$, Hu Jianjun ${ }^{4}$ \\ ${ }^{1}$ Key Laboratory of Crop Ecophysiology and Farming System in Southwest of China, Ministry of Agriculture/College of Agronomy, Sichuan \\ Agricultural University, Chengdu, China \\ ${ }^{2}$ Agricultural Extension Station of Dongpo District of Meishan City in Sichuan, Meishan, China \\ ${ }^{3}$ Ministry of Agriculture Key Laboratory of Tuber Crop Genetics and Breeding, Chengdu Jiusen Agricultural, Chengdu, China \\ ${ }^{4}$ Crop Institute, Sichuan Academy of Agricultural Sciences, Chengdu, China
}

Email address:

zhengshunlin123@163.com (Zheng Shunlin)

*Corresponding author

To cite this article:

Zhong Lei, Wang Liangjun, Yuan Jichao, Zheng Shunlin, Hu Jianjun. Plant Growth Regulators Affect Germination and Main Carbon-Nitrogen Metabolites of Potato Tubers. American Journal of Agriculture and Forestry. Vol. 7, No. 1, 2019, pp. 10-16. doi: 10.11648/j.ajaf.20190701.12

Received: November 6, 2018; Accepted: December 29, 2018; Published: January 30, 2019

\begin{abstract}
Assessing the effects of different growth regulators on sprout growth and tuber carbon-nitrogen metabolism during the storage of potato tubers is helpful to understand the physiological changes of dormancy in potatoes. In this study, a major potato cultivar 'Chuanyu-117' of Southwestern China was used as the experimental material. The tubers were immersed in sprouting inhibitors chlorpropham (CIPC), abscisic acid (ABA), and gibberellin $\mathrm{A}_{3}\left(\mathrm{GA}_{3}\right)$ to study sprout growth and changes in the carbon-nitrogen metabolism during tuber storage. The results showed that $\mathrm{GA}_{3}$ treatment shortened the dormancy intensity and amplitude by 17 days and 11 days, respectively, and that the sprouts grew faster after germination. Compared to the control treatment, ABA prolonged dormancy and increased its intensity by 6 days but shortened the amplitude by 11 days. After dormancy, the sprouts grew rapidly and uniformly. The CIPC treatment had a more significant dormancy prolonging effect. The stems germinated 70 days post treatment, and the germination period was extended by at least 40 days compared with the control. Tubers treated with different growth regulators showed similar carbon-nitrogen metabolism during the storage period. However, the rate of variation was significantly different. After 12 weeks, the starch content of tubers treated with $\mathrm{GA}_{3}, \mathrm{ABA}$, and CIPC decreased by $13.36 \%, 11.30 \%$, and $5.93 \%$, respectively, while soluble sugar content decreased by $48.3 \%, 58.9 \%$, and $56.1 \%$, respectively. Soluble protein and crude protein content in the treated tubers first increased and then decreased. Soluble protein content in the tubers treated with $\mathrm{GA}_{3}, \mathrm{ABA}$, and CIPC increased during storage but decreased in the later period. Crude protein content also increased the first time, and then decreased in the later period. Changes in the carbon-nitrogen ratio of tubers in different treatments during storage were also different. The carbon-nitrogen ratio of tubers treated with sprouting promotors was high, while that of the tubers treated with sprouting inhibitors was low and showed a gradual decreasing trend.
\end{abstract}

Keywords: Sprouting Inhibitor, Sprouting Promotor, Tuber, Germination, Carbon-Nitrogen Metabolism

\section{Introduction}

As the world's fourth largest food crop, potato has good nutritional and economic value and is widely used in the food, starch, feed, and pharmaceutical industries [1]. Storage of potato tuber, as a reproductive and vegetative organ, is one of the most important steps in the potato production chain. The quality of potato cultivation affects potato growth and yield quantity or quality, with the quality of commercial potatoes known to be directly linked to economic benefits [2,3]. After harvesting, because of the degree of dormancy in the potato storage process, irregular sprouts and shrinkage of tubers may occur, resulting in a decrease in nutritional, processing, and cultivation qualities of the tubers [4]. For potato production, in order to satisfy the demand of different sowing dates and to ensure the desired germination rate, germination uniformity, and growth potential, it is necessary to break or prolong the dormancy of potato cultivars in a timely and appropriate 
manner to adjust the dormancy period and the uniformity of germination [5]. When potatoes are used as processing and feed materials, it is necessary to extend the dormancy period to prolong the preservation time of tubers. Therefore, the dormancy regulation technology of potato tubers is of great significance to the actual production process. At present, research on dormancy regulation of potatoes has mainly considered the physical and growth regulator treatments. The former requires labor and material resources at high costs and the processing time is long, while the latter has the advantages of convenience, directness, and cost efficiency [6]. Gibberellin $\mathrm{A}_{3}\left(\mathrm{GA}_{3}\right)$ is considered to be the most effective agent for breaking potato tuber dormancy. However, the results of previous studies showed inconsistency in the suitable concentration and treatment method with different types, grades, and sizes of potato tubers $[7,8]$. Chlorpropham (CIPC) is a widely-used, high-efficiency potato sprouting inhibitor, and its inhibition effect has been widely reported [9-10]. In addition, abscisic acid (ABA) is considered to be a positive regulator for dormancy induction and may be involved in the maintenance of dormancy [11]. Its effect on prolonged dormancy has been demonstrated in onion and other crops [12], but it is rarely studied in potatoes as a sprouting inhibitor. Moreover, only a few comparative studies have investigated the effects of $\mathrm{ABA}, \mathrm{GA}_{3}$, and $\mathrm{CIPC}$ on the dormancy of potato tubers. In this experiment, the major potato cultivar 'Chuanyu-117' of Southwestern China was used as the experimental material to assess the effects of CIPC and $\mathrm{ABA}$ as sprouting inhibitors and $\mathrm{GA}_{3}$ as a sprouting promotor on the growth of sprouts and the carbon-nitrogen metabolism of potato tubers during storage. Furthermore, we investigated the dormancy regulation technology and its material basis, aiming to provide theoretical evidence for the scientific storage and processing of potato tubers.

\section{Materials and Methods}

\subsection{Experimental Materials}

The tested potato cultivar 'Chuanyu-117' is the primary cultivar of Southwest China. The test agents $\mathrm{GA}_{3}$ and ABA were manufactured by Chengdu Kelong Chemical Reagent Factory, whereas the Chlorpropham emulsifier (CIPC content $30 \%$ ) was developed by the Institute of Agricultural Product Storage and Processing, Gansu Academy of Agricultural Sciences.

\subsection{Experimental Methods}

After harvesting at the end of April 2014, potato tubers with good appearance, no mechanical damage, no disease, and a weight of approximately $50 \mathrm{~g}$ were selected. The selected tubers were washed and dried in a ventilated dark place and then divided into 4 parts. After 15 days, they were immersed in either $15 \mathrm{mg} / \mathrm{L}$ of $\mathrm{GA}_{3}$, CIPC emulsifier diluted 200 times (CIPC content of $1500 \mathrm{ppm}$ ), or $4 \mathrm{mg} / \mathrm{L}$ of ABA for $30 \mathrm{~min}$, and then they were dried and stored in the absence of light. Tubers immersed in water were used as control treatment (CK) for comparison. There were 6 replicates in each treatment, and each replicate contained 60 tubers. The treated potato tubers were placed in a box in a cool and ventilated place (storage temperature $18-24^{\circ} \mathrm{C}$, relative humidity $85-98 \%$ ). Three selected replicates were observed for germination, with records taken every day after treatment. The other three replicates were sampled at $0,14,28,42,56,70$, and $84 \mathrm{~d}$ after treatment to determine the dynamic changes of carbon-nitrogen metabolism. The whole potato was cured at $105^{\circ} \mathrm{C}$ for $30 \mathrm{~min}$ then dried at $80^{\circ} \mathrm{C}$ to a constant weight, after which it was ground and passed through a 100-mesh sieve for the determination of carbon-nitrogen metabolites.

\subsection{Measurements and Methods}

\subsubsection{Definition and Calculation of Gemination Dynamics Related Indicators of Each Treatment}

The germination dynamics of each potato tuber treatment was determined according to the method of Wang et al. [13, 14], and the relevant indicators were calculated as follows:

Germination rate: A 2-mm length of the first sprout on the tuber was used as the germination standard. The shoot length and diameter were measured with a Vernier caliper.

$$
\text { Germination rate }=\frac{\text { Germinated tubers }}{\text { Total tubers }} \times 100 \%
$$

Germination period: the number of days from the harvest of the tuber to $10 \%$ germination rate;

Dormancy period: the germination date of $50 \%$ of potato tubers was determined as the germination period of the treatment. The dormancy period was the number of days from harvest to the germination period;

Dormancy intensity: the number of days from harvest to $90 \%$ germination rate;

Dormancy amplitude: the number of days from $10 \%$ to $90 \%$ germination rates.

\subsubsection{Method for the Determination of Tuber Carbon-Nitrogen Metabolites}

Soluble sugar and starch content were determined by a sulfuric acid-anthrone method [15]. Crude protein content was determined by the Kjeldahl method. Soluble protein content was determined by the Coomassie Brilliant Blue G-250 method. Tuber carbon to nitrogen ratio $(\mathrm{C} / \mathrm{N})=$ soluble sugar content / soluble protein content [16].

\subsection{Data Analyses}

The test data was plotted and analyzed using Excel 2007, SPSS 20, and SigmaPlot 10.0.

\section{Results and Analysis}

\subsection{Effects of Different Growth Regulators on the Germination Rate During Storage Period of Potato Tubers}

The effects of different plant growth regulators on the germination dynamics of potato tubers during storage are 
presented in Table $1 . \mathrm{GA}_{3}$ showed a significant dormancy shortening effect. The germination and dormancy periods of treated tubers were 13 days and 20 days, respectively, earlier than those of the control treatments. The dormancy intensity and amplitude were of treated tubers were shortened by 20 days and 11 days, respectively, relative to the control. This indicates that $\mathrm{GA}_{3}$ can break dormancy, shorten the dormancy period, and improve the concentration and uniformity of germination to some extent. Contrary to $\mathrm{GA}_{3}$, ABA showed a dormancy prolongation effect. The germination and dormancy periods of tubers treated with ABA were delayed by 15 days and 4 days, respectively. The dormancy intensity was extended by 6 days, but the dormancy amplitude was also shortened by 11 days when compared with the control. This indicates that ABA has a significant sprout inhibition effect. ABA can extend the dormancy of potato tubers and greatly improve the uniformity of germination. The inhibition effect of CIPC was more significant. Tubers treated with CIPC began to germinate in 70 days and the germination rate was still less than $5 \%$ after 84 days of treatment, with the germination period delayed by at least 40 days compared with that of the control treatment.

The three growth regulators also had a significant effect on the germination process of potato tubers. As shown in Figure 1, the germination trend of potato tubers treated with $\mathrm{GA}_{3}$ and $\mathrm{CK}$ was slow-fast-slow, in line with the logistic function. The regression equation of the germination rate (Y) for the number of days after treatment (x, starting from the previous observation time at which germination was observed) for $\mathrm{GA}_{3}$ and $\mathrm{CK}$ was $\mathrm{Y}_{\mathrm{GA} 3}=97.67 /(1+$ $\left.\mathrm{e}^{(8.520-0.1993 \mathrm{x})}\right) \quad \mathrm{R}^{2}=0.9958^{* *}$ and $\mathrm{Y}_{\mathrm{CK}}=118.22 /(1+$ $\left.\mathrm{e}^{(6.048-0.0929 \mathrm{x})}\right) \mathrm{R}^{2}=0.9791^{* *}$, respectively. The germination process for the $\mathrm{ABA}$ treatment was more linear, and the regression equation was $\mathrm{Y}_{\mathrm{ABA}}=-193.66+3.5476 \mathrm{x}\left(\mathrm{R}^{2}=\right.$ $\left.0.9794^{* *}\right)$.

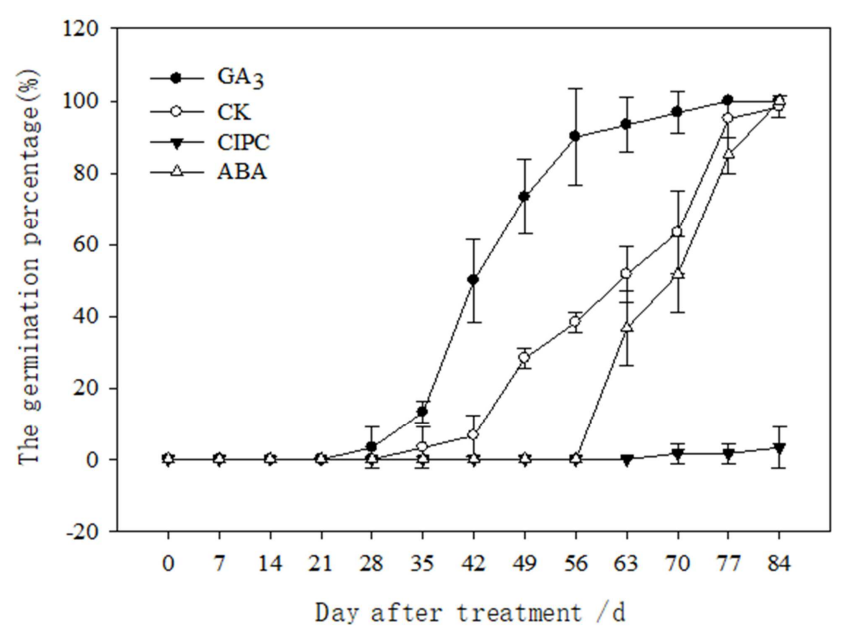

Figure 1. The germination percentage dynamics of potato after treatment with different growth regulators.
Table 1. Effects of different growth regulators on germination dynamics of 'Chuanyu-117'.

\begin{tabular}{lllll}
\hline Measurement & \multicolumn{4}{l}{ Growth regulators } \\
\hline Indexes & $\mathrm{GA}_{3}$ & $\mathrm{CK}$ & $\mathrm{CIPC}$ & $\mathrm{ABA}$ \\
Germination period (d) & $43 \mathrm{c}$ & $56 \mathrm{~b}$ & -- & $71 \mathrm{a}$ \\
Dormancy period (d) & $54 \mathrm{~b}$ & $74 \mathrm{a}$ & -- & $78 \mathrm{a}$ \\
Dormancy intensity (d) & $68 \mathrm{~b}$ & $85 \mathrm{a}$ & -- & $91 \mathrm{a}$ \\
Dormancy amplitude (d) & $20 \mathrm{~b}$ & $31 \mathrm{a}$ & -- & $20 \mathrm{~b}$ \\
\hline
\end{tabular}

Note: Values within a line followed by different lowercase letters are significantly different at 0.05 probability level, as determined by Duncan's multiple range tes.

\subsection{Effects of Different Growth Regulators on Dynamic Changes of Shoot Length and Diameter During the Storage of Potato Tubers}

The growth of potato sprouts is rapid after germination. The average shoot length (Y) of the sprouting tuber against the number of days after treatment was quadratic ( $\mathrm{x}$, starting from the previous observation time at which the germination was observed). The regression equations for $\mathrm{GA}_{3}, \mathrm{CK}$, and $\mathrm{ABA}$ treatment were $\mathrm{Y}_{\mathrm{GA} 3}=0.51-0.091 \mathrm{x}+$ $0.0028 \mathrm{x}^{2}\left(\mathrm{R}^{2}=0.9963^{* *}\right), \mathrm{Y}_{\mathrm{CK}}=3.83-0.210 \mathrm{x}+0.0028 \mathrm{x}^{2}$ $\left(\mathrm{R}^{2}=0.9891^{* *}\right)$, and $\mathrm{Y}_{\mathrm{ABA}}=11.14-0.440 \mathrm{x}+0.0043 \mathrm{x}^{2}\left(\mathrm{R}^{2}=\right.$ $\left.0.9868^{*}\right)$, respectively. $\mathrm{GA}_{3}, \mathrm{CIPC}$, and $\mathrm{ABA}$ not only affected the germination dynamics of tubers, but also significantly affected the growth of the sprouts. The average growth rate of shoot length during each germination period of $\mathrm{GA}_{3}$ and $\mathrm{ABA}$ treatments was higher than that of the control treatment. The average change in the germination rate during three periods of $10 \%$ to $50 \%, 50 \%$ to $90 \%$, and $90 \%$ to $100 \%$ germination rates was 0.122 , 0.188 , and $0.288 \mathrm{~mm} / \mathrm{d}$ for $\mathrm{GA}_{3}$ treatment, $0.089,0.183$, and $0.255 \mathrm{~mm} / \mathrm{d}$ for CK treatment, and $0.120,0.207$, and $0.272 \mathrm{~mm} / \mathrm{d}$ for ABA treatment, respectively. Although the average growth rate of shoot length after $\mathrm{GA}_{3}$ and $\mathrm{ABA}$ treatments was higher than that of $\mathrm{CK}$, the germination periods from $10 \%$ to $90 \%$ germination rates of the $\mathrm{GA}_{3}$ treatment and from $10 \%$ to $100 \%$ germination rates of the ABA treatment were shorter than those of the control treatment. Therefore, the average shoot length of these two treatments during the treatment period was relatively lower than that of the control treatment. The germination period from $90 \%$ to $100 \%$ germination rate of the $\mathrm{GA}_{3}$ treatment was longer than that of the control, and the shoot length was about $3 \mathrm{~mm}$ longer than the control treatment when the germination rate reached $100 \%$.

The growth of the shoot diameter was different from that of the shoot length. After germination, the shoot diameter increased linearly. The regression equation for the average shoot diameter $(\mathrm{Y})$ of tubers treated with $\mathrm{GA}_{3}, \mathrm{CK}$, and ABA against the number of days after treatment (x, starting from the previous observation time at which germination was observed) was $\mathrm{Y}_{\mathrm{GA} 3}=-1.63+0.0574 \mathrm{x}\left(\mathrm{R}^{2}=0.9885^{* *}\right)$, $\mathrm{Y}_{\mathrm{CK}}=-1.35+0.0503 \mathrm{x}\left(\mathrm{R}^{2}=0.0 .9501^{* *}\right)$, and $\mathrm{Y}_{\mathrm{ABA}}=-5.38$ $+0.0989 \mathrm{x}\left(\mathrm{R}^{2}=0.9805^{* *}\right)$, respectively. The average growth rate of shoot diameter in tubers treated with $\mathrm{GA}_{3}$, $\mathrm{CK}$, and ABA was $0.0574,0.0503$, and $0.0989 \mathrm{~mm} / \mathrm{d}$, 
respectively. The difference between $\mathrm{GA}_{3}$ and $\mathrm{CK}$ treatments was not significant, while there was a rapid increase in shoot diameter in the ABA treatment. However, because of a high germination rate and short germination period, the shoot diameter in the ABA treatment was still less than that of the $\mathrm{CK}$ and $\mathrm{GA}_{3}$ treatments at $100 \%$ germination.

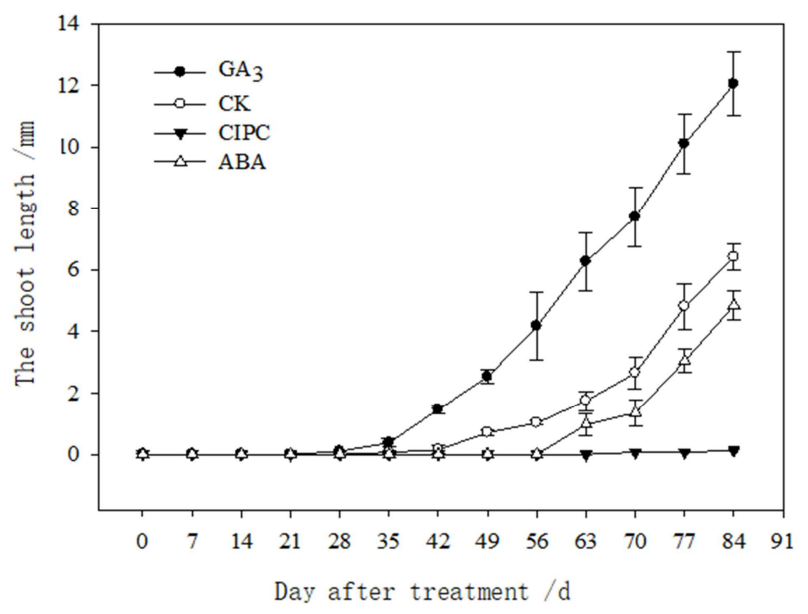

Figure 2. The shoot length dynamics of potato after treatment with different growth regulators.

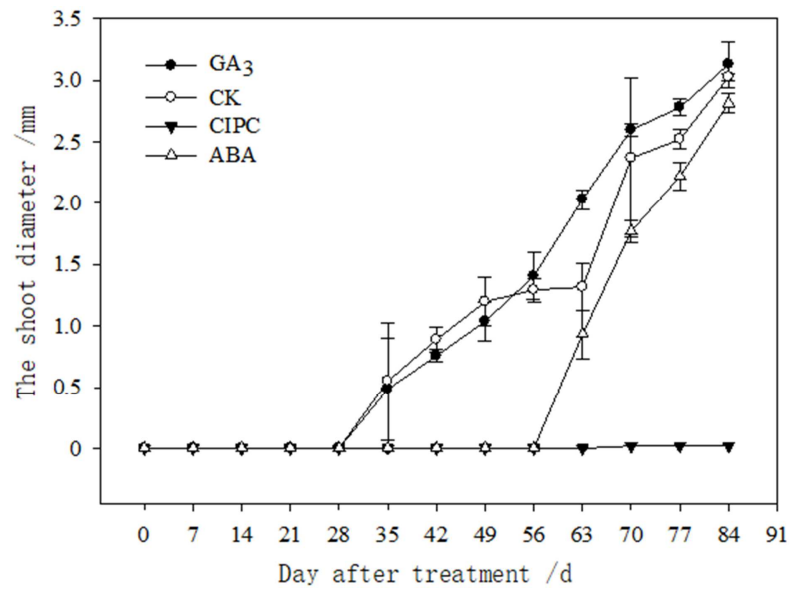

Figure 3. The shoot diameter dynamics of potato after treatment with different growth regulators.

\subsection{Effects of Different Growth Regulators on Carbon Metabolism During the Storage of Potato Tubers}

Figure 4 shows that starch content of the shoots during the storage of the treated tubers first increased and then decreased over the germination period. The starch content of tubers treated with $\mathrm{GA}_{3}, \mathrm{CIPC}$, and ABA increased to its highest after 14 days, 56 days, and 28 days after treatment, respectively, which was $4.6 \%, 5.1 \%$, and $2.3 \%$, respectively, higher than the starch content at the beginning of the experiment. Thereafter, the starch content of the tubers started to decrease, with the reduction amplitude of each treatment being different. The starch content of tubers treated with $\mathrm{GA}_{3}, \mathrm{CIPC}$, and ABA after 84 days was $13.36 \%, 5.93 \%$, and $11.30 \%$, respectively, lower than the starch content at the beginning of the treatment. During the early period of storage, the starch content of tubers in each treatment was not significantly different, and the differences only became significant after 42 days of treatment. During the later period of storage, the differences between $\mathrm{GA}_{3}$ and the control treatment and that between CIPC and ABA treatment were not significant, but the starch content of tubers treated with $\mathrm{GA}_{3}$ and the control treatment was significantly lower than that of the CIPC and ABA treatments. The soluble sugar content of the treated tubers varied during storage (Figure 5). GA 3 , CIPC, and the control treatments showed a decreasing trend, while ABA treatment showed a trend of first decreasing, then increasing, and then decreasing again. The reduction amplitude of soluble sugar content in tubers with different treatments was also different. After 84 days of treatment, the soluble sugar content of $\mathrm{GA}_{3}, \mathrm{CK}, \mathrm{CIPC}$, and $\mathrm{ABA}$ treatments was $48.3 \%, 57.5 \%, 58.9 \%$, and $59.1 \%$, respectively, lower than the soluble sugar content at the beginning of the treatments.

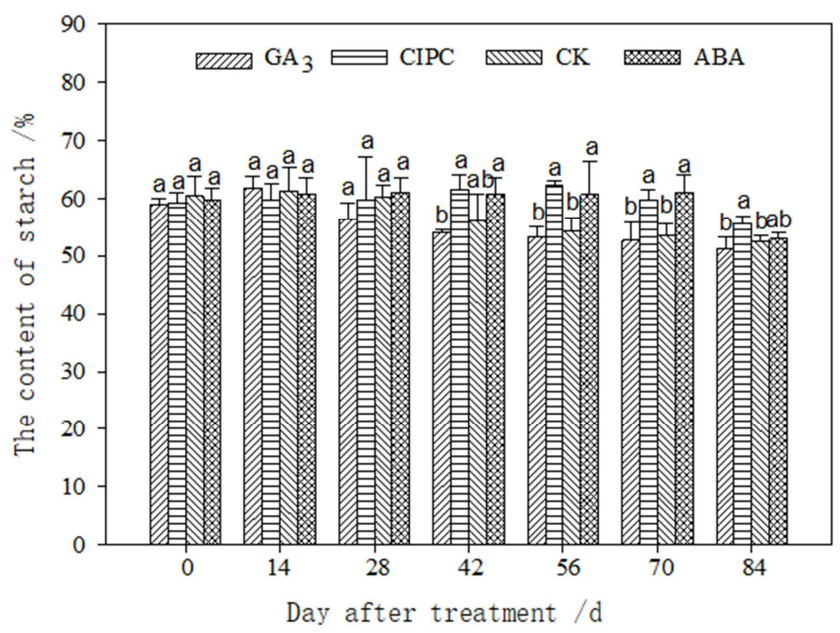

Figure 4. The change of the starch content in the potato tubers of different treatments during storage.

Note: Different lowercase letters above the columns show significant differences in starch content among treatments under the same storage period $(\mathrm{P}<0.05)$. The same as below.

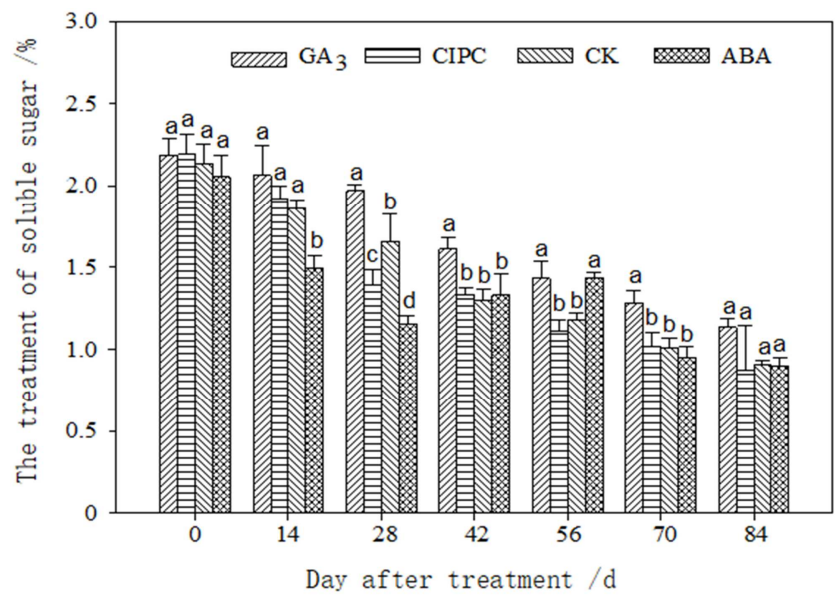

Figure 5. The change of the soluble sugar content of different treatments during storage. 


\subsection{Effects of Different Growth Regulators on Nitrogen Metabolism During the Storage of Potato Tubers}

As shown in Figure 6, soluble protein content of potato tubers in each treatment showed a trend of first increasing and then decreasing during the entire storage period. The difference between the treatments during the same period was not significant, but the soluble protein content started to decrease earlier in sprouting promotor treated groups than in that of sprouting inhibitor treated groups, and the content reached its maximum at around the germination period. During the early period of storage, the soluble protein content was maintained at a high level in tubers treated with the sprouting promotor $\mathrm{GA}_{3}$, and its increase was small. The soluble protein content remained at low levels in tubers treated with the sprouting inhibitors CIPC and ABA, but the protein content was higher in the ABA treatment than in the CIPC treatment. The increase in soluble protein content of each treatment was expressed as $\mathrm{ABA}(39.68 \%)>\mathrm{CK}(35.58 \%)>$ CIPC $(31.32 \%)>\mathrm{GA}_{3}(25.73 \%)$. The decrease in soluble protein content during the late storage period was $\mathrm{ABA}$ $(33.22 \%)>\mathrm{CK}(32.72 \%)>\mathrm{GA}_{3}(19.17 \%)>\mathrm{CIPC}(17.74 \%)$.

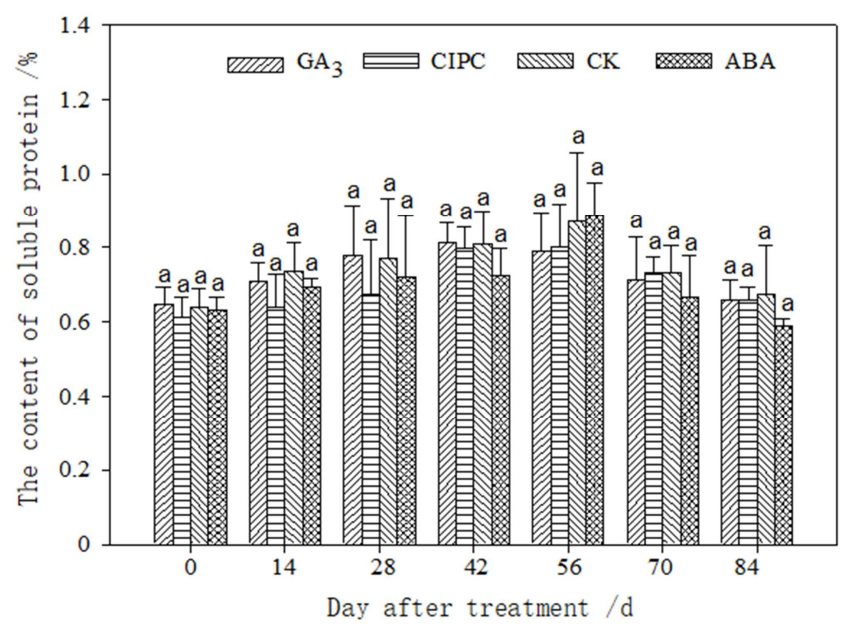

Figure 6. The change of soluble proteins of different treatments during storage.

Changes in crude protein content of the treated potato tubers during storage were similar to those of soluble proteins, with both showing a trend of first increasing and then decreasing; however, the changes in crude protein content were smaller (Figure 7). The crude protein content of each treated tuber increased to its highest level during the initial period of germination (about 28 days post treatment). The crude protein content in CIPC treated tubers increased the most during physiological dormancy and was significantly higher than in other treatments. After 14 days of treatment, the difference between sprouting promotor and inhibitor treatments was significant, but the difference within the sprouting inhibitor treatments was not significant. Later, with the prolongation of storage time, the difference in crude protein content between $\mathrm{GA}_{3}$ and $\mathrm{ABA}$ treatments was not significant but significantly varied compared with that in the CIPC treatment. The increase in crude protein content during the early period of storage was expressed as CIPC (12.8\%) > ABA $(12.5 \%)>\mathrm{CK}(8.2 \%)>$ $\mathrm{GA}_{3}(4.77 \%)$, while the decrease in crude protein content during the late storage period was $\mathrm{ABA}(18.02 \%)>\mathrm{CK}$ $(12.5 \%)>\mathrm{GA}_{3}(11.37 \%)>\mathrm{CIPC}(8.71 \%)$. This indicated that during the entire storage period, crude protein content was high in tubers treated with CIPC, whereas $\mathrm{GA}_{3}$ and $\mathrm{ABA}$ treatments decreased the crude protein content.

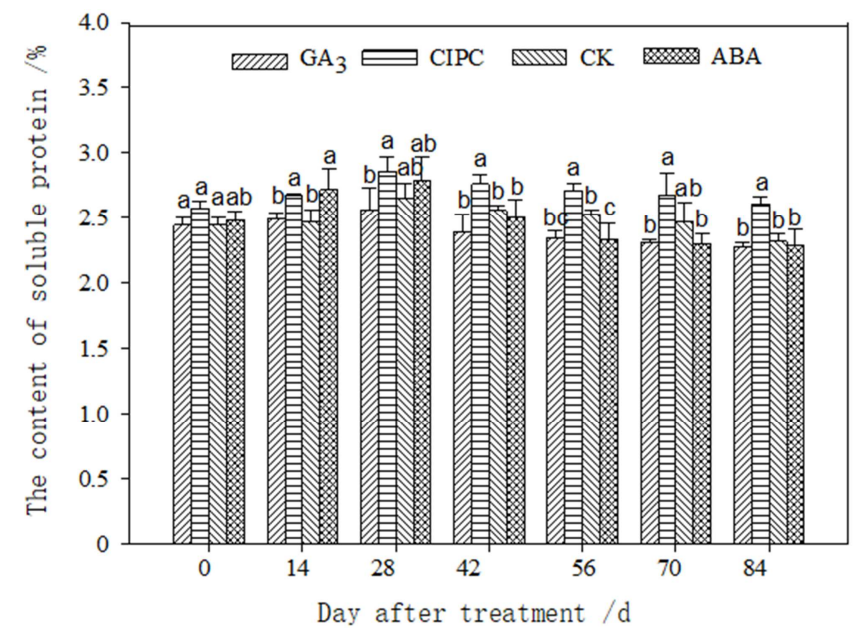

Figure 7. The change of the crude protein content of different treatments during storage.

\subsection{Effects of Different Growth Regulator Treatments on the Carbon-Nitrogen Ratio During the Storage of Potato Tubers}

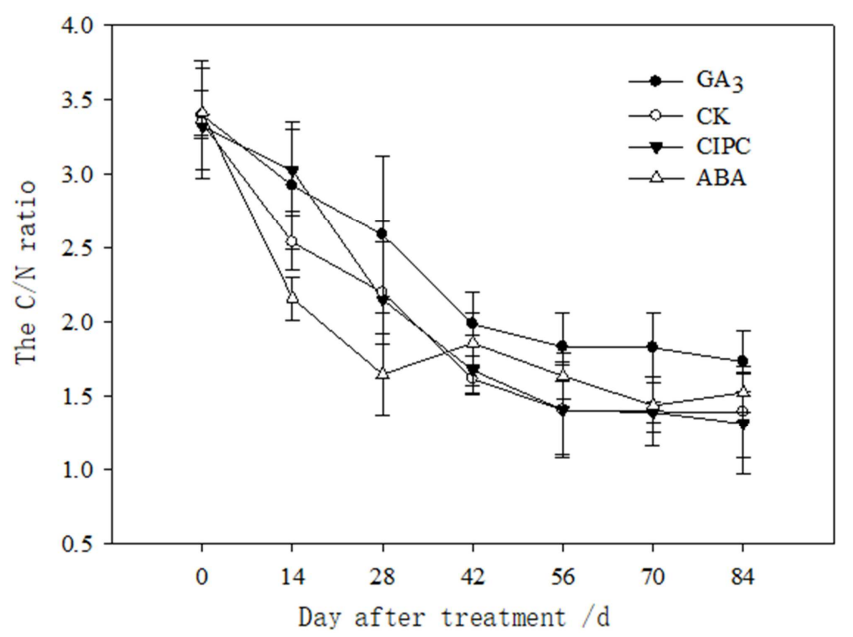

Figure 8. The change of the carbon-nitrogen ratio of different treatments during storage.

The carbon-nitrogen ratio of potato tubers treated with different growth regulators showed a decreasing trend except for ABA treatment, which increased gradually at about 42 days post treatment and then decreased thereafter (Figure 8). The effects of different growth regulator treatments on the carbon-nitrogen ratio of potato tubers were different. The carbon-nitrogen ratio of tubers treated with $\mathrm{GA}_{3}$ was higher than the overall level during the entire storage process. The carbon-nitrogen ratio of tubers treated with the sprouting inhibitor was relatively low. The decrease in the carbon-nitrogen ratio of tubers in each treatment 
during the entire storage period was expressed as CIPC $(60.44 \%)>\operatorname{CK}(58.40 \%)>\operatorname{ABA}(55.31 \%)>\mathrm{GA}_{3}(48.99 \%)$. However, the carbon-nitrogen ratio of tubers in the $\mathrm{ABA}$ treatment increased abruptly at the germination period, and the smaller decrease of carbon-nitrogen ratio after germination resulted in higher carbon-nitrogen ratios during the late storage period when compared with the CIPC and CK treatments, leading to a smaller decrease in the carbon-nitrogen ratio of the ABA-treated tubers.

\section{Discussion}

Potato tubers do not germinate immediately after harvest and require a period of post-ripening and physiological dormancy [17]. It is believed that the dormancy of potato tubers begins in the tuber formation period with the involvement of endogenous hormones for regulation [18, 19], and some plant growth regulators can regulate the dormancy of potato tubers. The results of the current study indicate that $\mathrm{GA}_{3}$ had significant dormancy breaking and germination-promoting effects. The dormancy period and dormancy intensity were shortened by 20 days and 17 days, respectively, and the dormant shoots grew rapidly after germination. However, young shoots (buds) were relatively slender, with a large shoot length to shoot diameter ratio. Therefore, for potato production, attention should be paid to the seedling hardening period, for ensuring that the seeding of potatoes occurs in a timely manner, with the amount of base fertilizer increased to cultivate strong seedlings. Contrary to the effect of $\mathrm{GA}_{3}, \mathrm{ABA}$ has a dormancy prolonging effect. Compared with the control treatment, after ABA treatment, the dormancy period and intensity of potato tubers increased by 4 days and 6 days, respectively, with high germination rate and germination uniformity. At the same time, the ratio of shoot length to shoot diameter was relatively small, and the young shoots (seedlings) were relatively thick, which is favorable for the cultivation of strong seedlings. Although the tubers treated with CIPC germinated during the experimental period, there was no obvious sign of sprout growth, indicating that CIPC has a strong inhibitory effect on tuber germination. Corsini et al. [20] reported that the CIPC content in the epidermis of the tubers gradually decreased due to factors such as CIPC volatilization or decomposition. When the CIPC content was less than $20 \mathrm{ppm}$, the potato germinated, but when the tubers were retreated with CIPC before the CIPC content was less than $20 \mathrm{ppm}$, the tubers remained dormant. Huang $\mathrm{Z}$ et al. found that the inclusion complex CIPC $\cdot H P \beta C D$ exhibited different properties from CIPC, and the complex displayed a better effect on sprout inhibition [21]. However, eventually, all tubers germinated, indicating that potato tubers treated with different concentrations of CIPC could all germinate. Therefore, for potato production, producers should choose the appropriate concentration of CIPC to treat potato tubers according to their needs.

A series of changes occur in the internal physiological activities and material transformations during the dormancy and germination periods of potato tubers. After harvesting, the potato tubers will first undergo corkification, preventing the invasion of pathogens and reducing the entry of oxygen. At this time, the physiological activity of the tubers is the same as that during "storage," which is mainly characterized by the conversion of soluble nutrients such as small molecules of sugars and amino acids into insoluble substances such as starch and protein through synthesis. Macromolecular nutrients can act as dehydration protectants that bind with water to facilitate a smooth dormancy period for the potatoes [22]. After dormancy, the tubers are transformed into "sources" and various metabolic activities start to increase [23]. Starch and protein begin to decompose into soluble sugars and soluble proteins. The former is the main energy-supplying substance and also an important osmoregulation and signaling substance [24]; the latter is the component of some metabolic enzymes, and it can enhance the water-holding capacity of the cells due to its hydrophilicity [25]. Therefore, these non-structural carbon-nitrogen compounds of tubers are important metabolic and energy substances, and the carbon-nitrogen ratio of tubers can provide a measure of the strength and coordination of the physiological activities [26, 27]. In this experiment, starch, crude protein, and soluble protein content of 'Chuanyu-117' tubers first increased and then decreased, reaching the maximum values at 14-56 days post treatment. However, the time at which the maximum content occurred varied depending on the treatment. The tubers in the $\mathrm{GA}_{3}$ treatment showed increased physiological activity, early decomposition of starch, faster decomposition rate, high soluble sugar content, and high carbon-nitrogen ratio. ABA treatment showed opposite trends; starch and protein began to decompose later and the carbon-nitrogen ratio during the early period of storage was relatively low. A study showed that exogenous GA3 inhibited tuber formation, whereas exogenous ABA stimulated tuberization, and $\mathrm{ABA}$ significantly promoted the accumulation of starch, suggesting that $\mathrm{ABA}$ may induce the expression of starch synthesis genes. The results of present study are consistent with the results of Yang, who reported that carbon and nitrogen are the material basis for $\mathrm{GA}_{3}$ and $\mathrm{ABA}$ to break or prolong tuber dormancy and promote or delay germination [28]. Therefore, tubers treated with $\mathrm{GA}_{3}$ and $\mathrm{ABA}$ should be planted soon after germination to avoid the aging of potato cultivars caused by excessive consumption of nutrients, preventing the loss of cultivation quality. The physiological activity of tubers treated with CIPC is in a low state. The content of nutrients such as starch and protein are relatively stable with low consumption rate. Therefore, CIPC can be used as a preservative for commercial potatoes.

\section{Conclusion}

$\mathrm{GA}_{3}$ can shorten tuber dormancy in potatoes, with tubers sprouting rapidly post dormancy with high nutrient consumption. In contrast, ABA can prolong potato tuber dormancy, with uniform tuber sprouting and high nutrient consumption during the later period. CIPC has the strongest inhibitory effect; it can effectively inhibit the germination and growth of potato sprouts, with less nutrient consumption. 


\section{Acknowledgements}

This research was supported by the National Key Research and Development Program (2018YFD0200808) and the Sichuan Provincial Breeding and Supporting Projects (2016NYZ0051-5, 2016NYZ0032).

\section{References}

[1] Chen Y Y. Research of the content change of dry matter, reducing sugar and starch in potato in the storage period. Chinese Agricultural Science Bulletin, 2006.22(4):84-87. (In Chinese with English abstract).

[2] Zhang W, Bai Y J, Li X Z, et al. Status quo and development trend of seed potato quality control. Chinese Potato Journal, 2010,24(3):186-189. (In Chinese with English abstract).

[3] Kenneth W, Knutson. Implication of new technologies for seed potato certification programs and seed growers. American Potato Journal. 1988,65(4):229-235.

[4] Yi J, Zhang X J, Ji L J, et al. How to realize potato's safe storage and appreciation of production of our country. (In Chinese).

[5] Zheng X H. Study on Mini Potato different storage method on seed vigor and physical and chemical properties. Gansu Agricultural University, 2010. (In Chinese with English abstract).

[6] Deng C L. Potato dormancy and its breaking methods. Chinese Potato Journal, 2010,24(3):151-152. (In Chinese with English abstract).

[7] Yang W L, Sui Q J. The dormancy characteristics of different gene type mini-tuber stuffs in potato breeding and their controlling. Southwest China Journal of Agricultural sciences, 2004,17(1):84-87. (In Chinese with English abstract).

[8] Li P H. Effects of different $\mathrm{GA}_{3}$ concentration on potato dormancy. Guizhou Agricultural Sciences, 2008,36(3):34-36. (In Chinese with English abstract).

[9] Zhong L, Deng J C, Wang L J, et al. Effect of plant growth regulators on germination and oxidase activity during storage of potato tubers. Acta Prataculturae Sinica,2017,(7):147-157. (In Chinese).

[10] Gale E, Kleinkopf, Nathan A. Oberg, et al. Sprout inhibition in storage: current status, new chemistries and natural compounds. American Journal Of Potato Research,2003,80:317-327.

[11] Elizabeth C. Schramm, Sven K. et al. Increased ABA sensitivity results in higher seed dormancy in soft white spring wheat cultivar 'Zak'. Theoretical and Applied Genetics,2013,126:791-803.

[12] Chen Q B, Hou X L, Wang J J, et al. Effect of exogenous abscisic acid on the dormancy of onion (Allium cepa). Journal of Nanjing Agricultural University, 2007,30(1):30-33. (In Chinese with English abstract).

[13] WANG C C, HU J J, JIA W W, et al. Effects of Gibberellin and Thiourea on Dormancy and Bud Morphogenesis of Pre-basic Potato under Different Tempertures. Southwest China Journal of Agricultural Sciences,2017,5:1035-1041. (In Chinese).
[14] Liu F, Yang Y J, Dong D F, et al. Study on dormancy characteristics of potato with different generations and weight. Shandong Agricultural Sciences, 2011,11:32-34. (In Chinese with English abstract).

[15] Xiong Q E. Plant physiology. Sichuan Science and Technology Press, 2003,81,82. (In Chinese).

[16] Zhou W X, Dong P F, Wang X P, et al. Effect of low-light stress on kernel setting and metabolism of carbon and nitrogen in different maize (Zea mays L.) genotypes. Acta Agronomica Sinica, 2013,39(10):1826-1834. (In Chinese with English abstract).

[17] Wu D P, Song M, Liu W B, et al. Advance in study on methods of maintaining and improving seed vigor. Seed, 2006,25(6):55-59. (In Chinese with English abstract).

[18] Zhang L L, Chen Y L, Lian Y. The dormancy of potato tuber and the advances in study on dormancy regulation. Chinese Potato Journal, 2003,17(3):352-356. (In Chinese).

[19] Luis Destefano-Beltran. Effects of postharvest storage and dormancy status on ABA content, metabolism and expression of genes involved in ABA biosynthesis and metabolism in potato tuber tissues. Plant Molecular Biology,2006,61:687-697.

[20] Corsini D, Stallknecht G, Spark W. Changes in chlorpropham residues in stored potatoes. American Potato Journal.1979,56(1):43-50.

[21] Huang Z, Tian S L, Ge X, et al. Complexation of chlorpropham with hydroxypropyl- $\beta$-cyclodextrin and its application in potato sprout inhibition .Carbohydrate Polymers, Volume 107, 17 July 2014, Pages 241-246.

[22] Liu L L, Li J, Li C H, et al. Evaluation of resistance level to late blight in the populations derived from the horizontal resistant crosses of potatoes. Chinese Potato Journal, 2004,18(4):201-204. (In Chinese with English abstract).

[23] Sun M L, Yang W L, Li S L, et al. Study on potato dormancy characteristics and control of sprout. Chinese Agricultural Science Bulletin, 2004,20(6):81-84. (In Chinese with English abstract).

[24] Sue Damon, John Hewitt, Matt Nieder et al. Sink Metabolism in tomato fruit. Plant Physiol,1988,87:731 736.

[25] Zhu Z, Jiang J Y, Jiang C J, et al. Effects of low temperature stress on SOD activity, soluble protein content and soluble sugar content in Camellia sinensis leaves. Journal of Anhui Agricultural University, 2011,38(1):24-26. (In Chinese with English abstract).

[26] Jiang Z J, Huang X P, Zhang J P. Effect of environmental stress on non-structural carbohydrates reserves and transfer in seagrasses. Acta Ecological Sinica, 2012,32(19):6242-6250. (In Chinese with English abstract).

[27] Yang J, Shi Y W, Li Z W, et al. Advance in study on the carbon and nitrogen metabolism of rice. Crop Research, 2011,25(4):383-387. (In Chinese).

[28] $\mathrm{Hu}$ Y Q, Zhan S, Ku W Z, et al. The Roles of ABA and GA3 in the Joint Regulation of Potato Tuber Formation and Starch Accumulation in Vitro. Molecular Plant Breeding, 2017,Vol.15, No.10, 4210-4214. (In Chinese with English abstract). 